\title{
DIREITOS HUMANOS E CIDADANIA: A PARTICIPAÇÃO NO SISTEMA INTERAMERICANO DE PROTEÇÃO DOS DIREITOS HUMANOS
}

\author{
HUMAN RIGHTS AND CITIZENSHIP: PARTICIPATION IN THE INTER- \\ AMERICAN HUMAN RIGHTS SYSTEM
}

\author{
Janaina Rigo Santin ${ }^{1}$ \\ Sheron Marcante ${ }^{2}$
}

\begin{abstract}
RESUMO - A participação - princípio constitucional - é um direito do cidadão brasileiro para que possa defender seus interesses. Recentemente os Direitos Humanos passaram por um processo de internacionalização e, a partir disso, a jurisdição para conhecer as violações de direitos humanos não é mais exclusiva do Estado em que ocorreu o fato, mas de toda a sociedade internacional. Esse movimento redefine o próprio conceito de cidadania ao ampliar a gama de direitos dos cidadãos. Portanto, as vítimas de violações de direitos humanos têm a possibilidade de buscar a reparação dos danos que Ihes foram causados através de um novo meio de participação, que consiste na formulação de denúncias a organismos internacionais de proteção aos direitos humanos. Assim, a presente pesquisa tem como objetivo desenvolver o tema dos direitos humanos com um enfoque internacional, mais especificamente sobre o Sistema Interamericano de Proteção dos Direitos Humanos como um novo meio eficaz dos cidadãos participarem.
\end{abstract}

PALAVRAS-CHAVE - Direitos Humanos. Princípio da Participação. Sistema Interamericano de Proteção aos Direitos Humanos.

\begin{abstract}
Participation - constitutional principle - is a Brazilian citizen's right to defend their interests. Human Rights recently went through a process of internationalization and, since that occurred, the jurisdiction over violations of human rights is no longer exclusive to the State in which the fact occurred, but to the whole international society. This movement redefines the very concept of citizenship by expanding the range of citizen's rights. Thus, victims of human rights violations have the possibility to seek repair for damages which were caused by a new way of participation, which consists in formulating denounces to international organisms of human rights protection. In this context, this research aims to develop the theme of human rights with an international focus, more specifically on the Inter-American Human Rights System as a new effective way for citizens to participate.
\end{abstract}

\footnotetext{
${ }^{1}$ Doutora em Direito pela UFPR. Mestre em Direito pela UFSC. Advogada. Professora e coordenadora de pesquisa da Faculdade de Direito da UPF. Membro docente permanente do programa de pós-graduação stricto sensu - mestrado em história da UPF. E-mail: janainars@upf.br.

${ }^{2}$ Graduanda em Direito pela Universidade de Passo Fundo (UPF), cursando o 8 semestre. Bolsista de Iniciação Científica FAPERGS. Tem experiência na área de Direito, com ênfase em Direito Público, atuando principalmente nos seguintes temas: princípios, sistema, direito, funções e normas. E-mail: sheron_marcante@hotmail.com.
} 
KEYWORDS - Human Rights. Inter-American Human Rights System.Principle of Participation.

\section{CONSIDERAÇÕES INICIAIS}

Com a globalização e a Era das Comunicações a sociedade civil superou o pensamento paradigmático de que a participação na gestão dos seus interesses seria possível apenas através do sufrágio e, então, passou a utilizar-se não só de meios institucionais para participarmas, também, de meios não convencionais.

Após presenciar as atrocidades cometidas durante a Segunda Guerra Mundial,a humanidade reconheceu a necessidade de criar uma sistemática internacionalde proteção aos direitos humanos com a finalidade de proteger todos os indivíduos, independentemente de sua nacionalidade e de onde se encontrassem. Esse processo de internacionalização dos direitos humanos tem como consequência dois benefícios incomensuráveis para os cidadãos:ampliação de seus direitos(a redefinição de cidadania) e a capacidade de pleitear seus interesses em organismos internacionais.

Nesse contexto, aparticipação dos cidadãos através do Sistema Interamericano de Proteção aos Direitos Humanos - sistema regional americano de proteção - surge como um novo meio dos cidadãos participarem, buscando a reparação dos danos que lhe foram causados e o restabelecimento de seu direito protegido internacionalmente.

\section{A PARTICIPAÇÃO}

Num sentido semântico mais geral, relacionadoespecialmente às ciências sociais, a participação é "uma forma ativa de integração de um grupo"(MOREIRA NETO, 2001, p. 12), ou seja - no sentido sociológico "participação significa 'fazer parte', 'tomar parte', 'ser parte' de um ato ou processo, de uma atividade pública, de ações coletivas"(TEIXEIRA, 2002, p. 28).

A Era das Comunicações e a globalização trouxeram consigo a possibilidade de ampla difusão de ideias e conhecimentos, causando a 
elevação dos índices de informação; bem como a sociedade atingiu níveis mais altos de educação. Consequênciadisso éo despertar da consciência dos cidadãos sobre os seus interesses, seu poder e sobre a influência que as decisões tomadas pelo Estado têm sobre si, levando-os a buscar espaço e meios de participação nas atividades desenvolvidas pelo ente estatal a fim de não ficarem submissos aos seus mandamentos(MOREIRA NETO, 2001, p. 12).Como bem acrescenta Lucas (1985, p. 112):

[...] uma sociedade participante é mais unida e coesa do que outra, na qual as pessoas se consideram apenas súditos, passivamente obedientes aos poderes constituídos, e não apoiadores ativos. Se cada um achar que as leis [como exemplo, porém, não somente isso, mas toda e qualquer decisão tomada pelo ente estatal] devem ser criadas por ele mesmo e sejam manifestações de sua própria vontade, então o problema da obediência política não só estará resolvido, como também o Estado se tornará incomensuravelmente mais forte e mais eficaz.

A partir disso, as pessoas não mais se conformaram em apenas escolher os seus representantes para que estes deliberem sobre os interesses da coletividade - em conformidade com o modelo de democracia representativa -, mas buscaram meios diretos de influir nas decisões do Estado, notadamente quanto à administração pública (MOREIRA NETO, 2001, p. 12-13).

Desse modo, superou-se a "consciência da personalidade", fundada no direito individual de participação e na autonomia privada, compondo-se basicamente do direito de votar e ser votado - característica do Estado Liberal - com a "consciência da sociedade", fundada no direito à participação coletiva e na autonomia coletiva, com a finalidade de enfrentar os desafios na busca de tutela dos interesses públicos específicos frente ao Estado (MOREIRA NETO, 2001, p. 13). Nas palavras de Moreira Neto (2006, p. 58):

[...] não mais bastando o consenso na escolha de pessoas pelo voto formal, trata-se de buscar um consenso mais amplo sobre a escolha de políticas públicas através de outras formas institucionais que possam disciplinar com fidelidade e segurança o processo de formação da vontade participativa [...].

Nesse contexto, a participação passou a ser sinônimo de "exercício da cidadania ativa", e as pessoas envolvidas nos processos participativos são considerados cidadãos (TEIXEIRA, 2002, p. 30). A partir desse entendimento, 
chega-se ao conceito de participação cidadã, sendo um "processo complexo e contraditório entre sociedade civil, Estado e mercado, em que os papéis se redefinem pelo fortalecimento dessa sociedade civil mediante a atuação organizada dos indivíduos, grupos e associações" (TEIXEIRA, 2002, p. 30). Ou seja, a participação atrelada ao conceito de cidadania consiste no desenvolvimento da sociedade civil -compreendida como uma "rede de associações autônomas, com interesses comuns, que devem exercer um controle sobre o Estado, utilizando-se para isso de meios não só institucionais, como não convencionais" (TEIXEIRA, 2002, p. 42) - frente ao Estado e ao mercado pela iniciativa dos cidadãos, na busca pela tutela dos interesses públicos.

Então, a cidadania ativa ocorre com a inserção integral das pessoas no processo político do Estado, que não se resume apenas no sufrágio, mas principalmente porque os cidadãos não se conformam com a utilização apenas dos meios de participação existentes e aqueles que estão por vir, mas buscam por novos meios que ganham legitimidade através do processo social (TEIXEIRA, 2002, p. 30-31), formando o que se chama de sociedade civil.

Ademais, Demo(1999, p. 18 e 23)ressalta que a participação é uma conquista significando:

[...] um processo, no sentido legítimo do termo: infindável, em constante vir-a-ser, sempre se fazendo. Assim, participação é em essência autopromoção e existe enquanto conquista processual. Não existe participação suficiente, nem acabada. Participação que se imagina completa, nisto mesmo começa a regredir.[...] a redução das desigualdades só pode ser fruto de um processo árduo de participação, que é conquista, em seu legítimo sentido de defesa de interesses contra interesses adversos.

Diante do exposto, conclui-se que a sociedade civil está numa busca constante de novos meios de participação cidadã, principalmente no que tange a administração pública, uma vez que as suas decisões têm efeitos diretos nos interesses (públicos) dos cidadãos que a compõe. Então, para assegurar o direito à participação dos cidadãos surge o Princípio Constitucional da Participação como diretriz das atividades desenvolvidas pelo Estado.

Ele decorre do Estado Brasileiro constituir-se em um Estado Democrático de Direito conforme prevê expressamente 0 artigo $1^{\circ}$ da Constituição Federal de 1988 e, ainda, da declaração feita no parágrafo único 
deste mesmo artigo de que todo o poder emana do povo (Princípio da Soberania Popular) e será exercitável pela representação e pela participação (MOREIRA NETO, 2006, p. 274- 275). Desse modo, é considerado um princípio implícito porque surge em razão do Princípio Democrático, ou seja, é intrínseco ao modelo do Estado Democrático de Direito, por conseguinte, não é necessário que esteja previsto explicitamente na Magna Carta (SANTIN, 2006, p. 6).

O Princípio da Participação dá o direito de os cidadãos participarem nas decisões tomadas pelo Estado para que façam valer os seus interesses, individuais e, principalmente, públicos. Assim, esse direito serve como uma defesa aos desmandos do ente estatal, protegendo os cidadãos de eventuais lesões ou danos causados por uma decisão arbitrária do Estado.

\section{O PROCESSO DE INTERNACIONALIZAÇÃO DOS DIREITOS HUMANOS: O INDIVÍDUO COMO SUJEITO DE DIREITO INTERNACIONALE A REDEFINIÇÃO DE CIDADANIA}

Os direitos humanos têm como causa a "necessidade de limitação e controle dos abusos de poder do próprio Estado e de suas autoridades constituídas" (MORAES, 2011, p. 1). A partir dessa constatação começa a se desenvolvera proteção internacional dos direitos humanos - e, consequentemente, o Direito Internacional dos Direitos Humanos - como um meio de reparar os danos já causados e evitar novas lesões causadas pelo Estado aos seus nacionais(com a finalidade de dar efetividade aos direitos humanos).

Uma das primeiras manifestações sobre a necessidade de uma legislação internacional para a consecução da paz - sendo ela o "pressuposto necessário para o reconhecimento e a efetiva proteção dos direitos do homem em cada Estado e no sistema internacional" (BOBBIO, 1992, p. 1) - foi feita por Kant, pensador do último período do lluminismo, que durante o "período do Terror" (1793-1794) percebeu a importância da relação entre a ética e a política por meio do direito, mais precisamente (neste caso), o direito internacional. Imergido nesse contexto, o autor salienta que para haver paz e, 
consequentemente, salvaguardar os direitos dos nacionais dos Estados são necessárias normas internacionais, às quais todos os Estados estejam submetidos (havendo uma consequente limitação da sua soberania).Isto é, uma legislação superior que unisse todos os Estados para a consecução de um mesmo objetivo: alcançar a paz. Assim, o direito internacional deveria fundarse em um federalismo de Estados livres (KANT, 2010, p. 7 et seq.), como exemplifica o filósofo (2010, p. 35):

É compreensível que um povo diga: 'não deve haver guerra entre
nós, pois queremos formar um Estado, isto é, estabelecer um poder
supremo legislativo, executivo e judiciário que concilie nossas
desavenças pacificamente'. Quando, porém, este Estado diz: 'não
deve haver guerra entre mim e outros Estados, apesar de eu não
reconhecer nenhum poder legislativo supremo que assegure a mim o
meu direito e ao qual asseguro o seu', então não se compreende
sobre o que quero fundar a confiança no meu direito, a não ser no
substituto da liga de sociedade civil, a saber, o livre federalismo, que
a razão tem de ligar necessariamente ao conceito de direito
internacional [...].

Ademais, Kant (2010, p. 12-36) sustenta que enquanto o direito internacional for o "direito para a guerra" não haverá lugar para uma "república mundial", que poderia impedir a inclinação hostil dos Estados, formando uma "liga consistente, sempre expansiva e que repele a guerra". Analisando-se de modo contemporâneo, pode-se dizer que o autor prevê a formação da Liga das Nações e da Organização das Nações Unidas.

O processo de internacionalização dos direitos humanos teve início após a Primeira Guerra Mundial, em1914, com o Direito Humanitário, que é o direito que é aplicado no caso de guerras, com a finalidade de impor limites à atuação estatal e garantir que os direitos humanos sejam respeitados, destinando-se à população envolvida na guerra e aos militares feridos, doentes ou prisioneiros. Essa foi a manifestação pioneira no sentido de impor limites à liberdade e à autonomia dos Estados na esfera internacional. Para reforçar essa necessidade de relativizar a soberania estatal surgiu a Liga das Nações que, conforme o preâmbulo da Convenção da Liga das Nações de 1920, tem a finalidade de promover a cooperação internacional, alcançar a paz e a segurança internacional, condenando agressões externas contra a integridade territorial e a independência política dos seus membros e, também, estabelecer sanções econômicas contra os Estados que não cumprirem suas obrigações 
para com a sociedade internacional. Tal convenção continha algumas previsões sobre direitos humanos, como as referentes ao sistema de minorias e aos parâmetros internacionais do direito do trabalho. Ao lado do Direito Humanitário e da Liga das Nações, surge a Organização Internacional do Trabalho (OIT), tendo como finalidade promover padrões internacionais de condições de trabalho e de bem-estar dos trabalhadores (PIOVESAN, 2008, p. 109 et seq.).

Todos esses institutos criados após a primeira guerra contribuíram, cada qual de seu modo, para o processo de internacionalização dos direitos humanos; marcando o fim de uma época em que o Direito Internacional era considerado, tão somente, um conjunto de normas relativas às relações entre Estados em âmbito governamental (PIOVESAN, 2008, p. 111 et seq.). Ainda, no mesmo sentido, Piovesan (2008, p. 115) salienta que:

Tais institutos rompem, assim, com o conceito tradicional que situava - Direito Internacional apenas como a lei da comunidade internacional dos Estados e que sustentava ser o Estado o único sujeito de Direito Internacional. Rompem ainda com a noção de soberania nacional absoluta, na medida em que admitem intervenções no plano nacional, em prol da proteção dos direitos humanos.

Entretanto, só começa a se formar efetivamente um sistema internacional de proteção aos direitos humanos com o advento da Segunda Guerra Mundial, em decorrência das repugnantes violações aos direitos humanos da era Hitler (nazismo) e da esperança de que futuras violações poderiam ser evitadas através de uma proteção internacional desses direitos.

Num cenário de barbárie, em que se o valor da pessoa humana é anulado, como se não existisse dignidade por serem as pessoas consideradas "descartáveis", é imprescindível a reconstrução dos direitos humanos como "paradigma e referencial ético a orientar a ordem internacional contemporânea" para aproximar o direito da moral, uma vez que nasce a certeza de que a proteção de tais direitos é de interesse internacional (PIOVESAN, 2008, p. 118119).

O reconhecimento da necessidade de intervenção internacional para proteção das pessoas impulsionou o processo de internacionalização dos 
direitos humano e, por isso, foi criada uma sistemática internacional de proteção aos direitos humanos (a criação das Nações Unidas e a adoção da Declaração Universal dos Direitos do Homem pela Assembleia Geral da ONU em 1948). Assim, a partir do final do século XX, os Estados que violarem direitos ou se mostrarem falhos ou omissos na sua proteção poderão ser responsabilizados pelos danos causados através de um órgão internacional (PIOVESAN, 2008, p. 119).

Além disso, através do Acordo de Londres, o Tribunal de Nuremberg (1945 a 1946) é um marco na proteção internacional dos direitos humanos, uma vez que fundamentou a decisão de condenar os indivíduos pela violação do costume internacional - entendido como "prática geral e comum aceita como lei". Então, a importância do Tribunal de Nuremberg para a internacionalização dos direitos humanos é demonstrada em dois aspectos: a) evidencia a necessidade de limitação da soberania dos Estados; e b) reconhece os indivíduos como sujeitos de Direito Internacional, tendo os seus direitos protegidos não somente pelo Estado de que são nacionais (PIOVESAN, 2008, p. 120 et seq.). E corroborando com esta ideia afirma Pereira (1997, p. 405-406):

De facto, o indivíduo não é hoje visto pelo ordenamento jurídico internacional apenas como objecto de simples protecção diplomática da parte do Estado de que é nacional (o que em si mesmo encerrava uma grande fragilidade, não só porque em tal situação o indivíduo não se encontrava garantido contra o Estado de que era nacional como também porque, sendo aquela protecção uma mera faculdade, nenhum Estado iria proteger o indivíduo contra os seus próprios interesses políticos), mas é considerado verdadeiro sujeito de direitos e obrigações que o Direito Internacional the reconhece de modo directo e imediato.

Outro grande marco referencial que fortaleceu a proteção internacional ocorreu em 1945 com a criação da Organização das Nações Unidas (ONU).Desde então, os Estados que aderirem à Carta das Nações Unidas reconhecem que o tema dos direitos humanos têm relevância internacional e, por isso, não devem ser objeto de exclusiva jurisdição interna (PIOVESAN, 2008, p. 126 et seq.). Além disso, como lembra Comparato (2010, p. 69):

Após o término da $2^{a}$ Guerra Mundial, dezenas de convenções internacionais, exclusivamente dedicadas à matéria, foram celebradas no âmbito da Organização das Nações Unidas ou das 
organizações regionais, e mais de uma centena foram aprovadas no âmbito da Organização Internacional do Trabalho. Não apenas os direitos individuais, de natureza civil e política, ou de direitos de conteúdo econômico e social foram assentados no plano internacional. Afirmou-se também a existência de novas espécies de direitos humanos: direitos dos povos e direitos da humanidade.

Ainda, em 1948 advém a Declaração Universal dos Direitos Humanos para complementar a Carta das Nações Unidas e definir com precisão quais são os "direitos humanos e liberdades fundamentais" a que este diploma se refere. Assim, "é como se a Declaração, ao fixar um código comum e universal dos direitos humanos, viesse a concretizar a obrigação legal relativa à promoção desses direitos - obrigação esta constante da Carta das Nações Unidas" (PIOVESAN, 2008, p. 132). Este diploma traça um conjunto de faculdades e direitos imprescindíveis para o desenvolvimento físico, moral e intelectual da pessoa humana; definindo um consenso sobre os valores universais que devem ser seguidos por todos os Estados para formar uma ordem pública mundial com fundamento na dignidade da pessoa humana ${ }^{3}$. Consequentemente, tem como característica marcante a universalidade, ou seja, as normas contidas em seu texto são aplicáveis a todas as pessoas indistintamente (não se perquirindo raça, religião ou sexo), seja qual for 0 regime político adotado pelo Estado - o único requisito para ser sujeito de direitos é a condição de pessoa. Também traz consigo a noção de indivisibilidade, uma vez que é a pioneira em conjugar os direitos de primeira dimensão (direitos civis e políticos) com os direitos econômicos, sociais e culturais ${ }^{4}$; com a intenção de explicitar a igualdade de importância de todos

\footnotetext{
3 "La dignidad de la persona humana es el fundamento de los derechos con los que el hombre defiende los bienes esenciales de su personalidad frente a las demás personas y del estado. Esos bienes son: la libertad (de su espíritu), la vida (que emana de su cuerpo material) y el trabajo, que es una manifestación de su personalidad (unidad esencial de espíritu y materia), de los que surgen los derechos a la libertad, a la vida e al trabajo, y de los que derivan el resto de los derechos humanos." (GENTILE, 2005, p. 62)

${ }^{4}$ Fala-se, geralmente, sobre três gerações de direitos humanos. No entanto, "não há como negar que o reconhecimento progressivo de novos direitos fundamentais tem o caráter de um processo cumulativo, de complementaridade, e não de alternância, de tal sorte que o uso da expressão 'gerações' pode ensejar a falsa impressão da substituição gradativa de uma geração por outra", assim, prefere-se, atualmente, o termo "dimensões". Os direitos fundamentais de primeira geração consistem nos "direitos dos indivíduos frente ao Estado" - os direitos civis e políticos -, compreendendo os direitos à vida, à liberdade, à propriedade, à igualdade perante a lei, às liberdades de expressão coletiva, à participação política e às garantias processuais. Os direitos econômicos, sociais e culturais de segunda dimensão "caracterizam-se [...] por outorgarem ao indivíduo direitos a prestações sociais estatais, como assistência social, saúde, educação, trabalho, etc...". Os direitos de solidariedade e fraternidade de terceira dimensão
} 
esses direitos e afirmar a interdependência e a relação entre esses direitos. ${ }^{5}$ Por tudo isso, a Declaração Universal dos Direitos Humanos dá moldes ao conceito contemporâneo de direitos humanos.

Deste modo, pode-se definir genericamente os direitos humanos como:

O conjunto institucionalizado de direitos e garantias do ser humano que tem como finalidade básica o respeito a sua dignidade, por meio de sua proteção contra 0 arbítrio do poder estatal, e 0 estabelecimento de condições mínimas de vida e de desenvolvimento da personalidade humana. (MORAES, 2011, p. 20)

E numa concepção mais abrangente acerca dos direitos humanos, podese afirmar que estes constituem:

[...] um conjunto de faculdades e instituições que, em cada momento histórico, concretizam as exigências da dignidade, da liberdade e da igualdade humanas, as quais devem ser reconhecidas positivamente pelos ordenamentos jurídicos em nível nacional e internacional. (MORAES, 2011, p. 20-21)

Convém, aqui, diferenciar os termos "direitos humanos" e "direitos fundamentais". Este último se refere àqueles direitos inerentes à pessoa humana que estão positivados nas Constituições escritas dos Estados; ao passo que aquele é usado para referir-se aos direitos, também intrínsecos à condição humana, que tem relação com os documentos de direito internacional, independentemente de estarem vinculados, ou não, a uma determinada ordem constitucional, pois "aspiram à validade universal, para todos os povos e tempos, de tal sorte que revelam um inequívoco caráter supranacional (internacional)". Isto é, o critério para a diferenciação é a da "concreção positiva": os direitos fundamentais são o conjunto de direitos "reconhecidos ou outorgados e protegidos pelo direito constitucional interno de

\footnotetext{
"caracterizam-se [...] como direitos de titularidade coletiva ou difusa", englobando os direitos à paz, à autodeterminação dos povos, ao desenvolvimento, ao meio ambiente e qualidade de vida e, também, o direito à conservação e utilização do patrimônio histórico cultural e o direito de comunicação. (SARLET, 2009, p. 45 et. seq.)

${ }^{5}$ A autora explicita a indivisibilidade dos direitos humanos quando salienta que: “... revela-se esvaziado o direito à liberdade, quando não assegurado o direito à igualdade e, por sua vez, esvaziado revela-se o direito à igualdade, quando não assegurada a liberdade. Vale dizer, sem a efetividade dos direitos econômicos, sociais e culturais, os direitos civis e políticos se reduzem a meras categorias formais, enquanto que, sem a realização dos direitos civis e políticos, ou seja, sem a efetividade da liberdade entendida em seu mais amplo sentido, os direitos econômicos e sociais carecem de verdadeira significação. Não há mais como cogitar da liberdade divorciada da justiça social, como também infrutífero pensar na justiça social divorciada da liberdade." (PIOVESAN, 2003, p. 37)
} 
cada Estado", enquanto os direitos humanos estão positivados na esfera do direito internacional (SARLET, 2009, p. 29-33).

Além de tornar os indivíduos - nacionais de determinado Estado sujeitos de direito internacional dotados de capacidade processual, a universalização dos direitos humanos (e o Direito Internacional dos Direitos Humanos) tem como consequência, também, a redefinição do próprio conceito de cidadania.

O conceito clássico de cidadania que englobava tão somente a nacionalidade e os direitos políticos foi superado durante a história com a conquista de novos direitos, até chegar um conceito mais moderno em que cidadania e direitos humanos praticamente se confundem (CORRÊA, 2002, p. 210 et seq.). Nesse contexto, o alcance do que se concebe por cidadania é ampliado, eis que incorpora, também, direitos que não estão previstos no direito interno do Estado de que é nacional, ou seja, que estão positivados internacionalmente. Por conseguinte, o desconhecimento dos direitos positivados internacionalmente - os direitos humanos - acarreta no desconhecimento de grande parte dos direitos que compõe a cidadania, e significa a "privação do exercício de direitos acionáveis e defensáveis na arena internacional". Desse modo, pode-se, atualmente, afirmar que "a realização plena, e não apenas parcial dos direitos da cidadania, envolve o exercício efetivo e amplo dos direitos humanos, nacional e internacionalmente assegurados" (PIOVESAN, 2003, p. 71-72).

Em suma, o movimento de internacionalização de direitos humanos por ser tema de interesse internacional -, embora ainda recente, traz consigo

\footnotetext{
${ }^{6}$ Ainda sobre a terminologia frisa o autor: "A consideração de que o termo "direitos humanos" pode ser equiparado ao de "direitos naturais" não nos parece correta, uma vez que a própria positivação em normas de direito internacional, de acordo com a lúcida lição de Bobbio, já revelou, de forma incontestável, a dimensão histórica e relativa aos direitos humanos, que assim se desprenderam - ao menos em parte (mesmo para os defensores de um jusnaturalismo) - da ideia de um direito natural. Todavia, não devemos esquecer que, a sua vertente histórica, os direitos humanos (internacionais) e fundamentais (constitucionais) radicam no reconhecimento, pelo direito positivo, de uma série de direitos naturais do homem, que, neste sentido, assumem uma dimensão pré-estatal e, para alguns, até mesmo supraestatal. Cuida-se, sem dúvida, igualmente de direitos humanos - considerados como tais aqueles outorgados a todos os homens por sua condição humana -, mas, neste caso, de direitos não-positivados." E mais adiante sobre a melhor terminologia a ser adotada destaca "o uso mais recente da expressão 'direitos humanos fundamentais' por alguns autores. De acordo com Sérgio Rezende de Barros, que refuta a tese da distinção entre direitos humanos e fundamentais, esta designação tem a vantagem de ressaltar a unidade essencial e indissolúvel entre direitos humanos e direitos fundamentais." (SARLET, 2009, p. 29-33)
} 
duas vantagens para o direito e para os cidadãos: as pessoas tornam-se sujeitos de direito internacional com capacidade processual para pleitear seus direitos em organismos internacionais e o conceito de cidadania torna-se muito mais abrangente, compondo-se dos direitos positivados nos documentos nacionais e internacionais. Tudo isso serve para dar efetividade aos direitos humanos e fundamentais, possibilitando a participação cidadã das pessoas nos sistemas regionais e internacionais de proteção aos direitos humanos.

\section{O SISTEMA INTERAMERICANO DE PROTEÇÃO AOS DIREITOS HUMANOS}

Como ressalta Bobbio: "o problema fundamental em relação aos direitos do homem, hoje, não é tanto de justificá-los, mas o de protegê-los"(BOBBIO, 1992, p. 24). Para tanto, tornou-se necessário, com a universalização dos direitos humanos, criar uma sistemática normativa internacional cogente - os Sistemas Internacionais de Proteção aos Direitos Humanos -. E para tornar verdadeiramente eficazes esses direitos (dando efetividade ou "juridicidade" aos direitos descritos na Declaração Universal dos Direitos Humanos) surgiram os Sistemas Regionais de Proteção aos Direitos Humanos (PIOVESAN, 2008, p. 157 et seq.).

No entanto, é importante frisar que a proteção internacional dos direitos não substitui ou afasta a proteção interna. Primeiramente, a proteção aos direitos dos indivíduos deve ser dada pelo Estado de que são nacionais e de modo subsidiário deverá se recorrer aos sistemas internacionais. Corroborando tal entendimento, mais especificamente sobre o Sistema Regional de Proteção, frisa Mazzuoli (2011, p. 882):

A proteção dos direitos humanos prevista na Convenção Americana é coadjuvante ou complementar da que oferece o Direito interno dos seus Estados-partes [...]. Tal significa que não se retira dos Estados a competência primária para amparar e proteger os direitos das pessoas sujeitas à sua jurisdição, mas que nos casos de falta de amparo ou de proteção aquém da necessária, pode o sistema interamericano atuar concorrendo para o objetivo comum de proteger determinado direito que o Estado não garantiu ou preservou menos do que deveria. 
Desse modo, o sistema global e o regional promotores dos direitos humanos não são incompatíveis entre si, mas complementares. Tais sistemas guardam harmonia entre si, uma vez que o seu conteúdo normativo deve ser similar e compatível, devendo refletir os valores expressos na Declaração Universal dos Direitos Humanos. Ao sistema global caberá positivar os direitos e garantias mínimos, enquanto os sistemas regionais devem adicionar novos direitos, aperfeiçoando-se conforme as peculiaridades de sua região. Diante dessa variedade de instrumentos internacionais à disposição, caberá ao indivíduo escolher qual deles será mais benéfico para a reparação do dano que sofreu (PIOVESAN, 2008, p. 241-242).

Os sistemas internacionais de proteção dos direitos humanos podem ter diferentes âmbitos de aplicação: global ou regional. O sistema global é composto por todos os instrumentos produzidos pela Organização das Nações Unidas, uma vez que esta representa todos os Estados-partes de todas as regiões do mundo; assim, a sua incidência não se limita a uma região específica, podendo atingir qualquer Estado da comunidade internacional que Ihe faça parte. Já o sistema regional cuida da proteção dos direitos humanos de uma determinada região e, por isso, a sua incidência está limitada a ela. Os sistemas regionais existentes compreendem: o da América, da Europa e da África, tendo cada qual um aparato jurídico próprio (PIOVESAN, 2008, p. 237 et seq.).

O Sistema Interamericano, do qual o Estado Brasileiro faz parte, tem como instrumento fundamental a Convenção Americana de Direitos Humanos de 1969 - também denominada Pacto de San José da Costa Rica (eis que o encontro para a sua celebração ocorreu neste local) -, que entrou em vigor internacional em julho de 1978, tendo sido ratificada pelo Brasil no ano de 1992 e promulgada internamente pelo Decreto oㅜ 678 , de seis de novembro deste mesmo ano (MAZZUOLI, 2011, p. 882).

Somente podem aderir a esta Convenção os Estados membros da Organização dos Estados Americanos (OEA); sendo que, segundo dados da 
Organização, dos 34 Estados que fazem parte da OEA, 24 fazem parte, atualmente, também da Convenção ${ }^{7}$.

Os Estados-partes tem a obrigação de, nos termos do artigo 1ํㅜ 1 , da Convenção Americana, "respeitar os direitos e liberdades nela reconhecidos e a garantir seu livre e pleno exercício a toda pessoa que esteja sujeita à sua jurisdição, sem discriminação alguma por motivo de raça, cor, sexo, idioma, religião, opiniões políticas ou de qualquer outra natureza, origem nacional ou social, posição econômica, nascimento ou qualquer outra condição social". Isto é, a proteção da Convenção se estende tanto aos nacionais dos Estados quanto aos estrangeiros e apátridas que estiverem sob a sua jurisdição no momento em que ocorrer a violação de direitos humanos. Também terão os membros a obrigação de "adotar, de acordo com as suas normas constitucionais e com as disposições desta Convenção, as medidas legislativas ou de outra natureza que forem necessárias para tornar efetivos tais direitos e liberdades", no caso de ainda não haver disposição legislativa ou outra que os garanta (MAZZUOLI, 2011, p. 882-883).

Ainda, para o monitoramento e a implementação - na verdade, a efetivação - dos direitos que estabelece a Convenção de Direitos Humanos, foram instituídos dois aparatos: a Comissão Interamericana de Direitos Humanos e a Corte Interamericana de Direitos Humanos(PIOVESAN, 2008, p. 246).

\subsection{Comissão Interamericana de Direitos Humanos}

A Comissão Interamericana de Direitos Humanos foi criada em 1959 e começou a funcionar em 1960, tendo como função, de acordo com o seu primeiro estatuto, "promover os direitos estabelecidos tanto na Carta da Organização dos Estados Americanos, quanto na Declaração Americana dos Direitos e Deveres do Homem"(MAZZUOLI, 2011, p. 884). Assim sendo, sua jurisdição alcança todos os Estados-membros da Convenção Interamericana e, também, todos os Estados que fazem parte da OEA, nesse caso, em relação

\footnotetext{
${ }^{7}$ Dados retirados de: <http://www.oas.org/juridico/english/Sigs/b-32.html>. Acesso em 5 de novembro de 2011.
} 
somente aos direitos elencados na Declaração Americana de 1948 (PIOVESAN, 2008, p. 247).

A Comissão - sediada em Washington, Estados Unidos, juntamente com a sede da Organização dos Estados Americanos - é integrada por sete membros, que deverão ter "alta autoridade moral e reconhecido saber em matéria de direitos humanos", ao teor do disposto no artigo 34 da Convenção Americana. A eleição é feita em Assembleia Geral da OEA, sendo que os candidatos são propostos pelos governos de cada Estado-parte. O mandato tem duração de quatro anos. E é vedada a eleição de mais de um nacional do mesmo país para a composição da Comissão (GORESTEIN; HIDAKA; LIMA JR., 2002, p. 83 et seq.).

Sobre a criação, função e composição da Comissão Interamericana, resumem Bragato, Culleton e Fajardo (2009, p. 131):

\begin{abstract}
Foi somente em 1959, quando a V Reunião de Consulta de Ministros de Relações Exteriores, baseada no artigo $5^{\circ}$, j, da Carta da OEA, criou a Comissão Interamericana de Direitos Humanos, que, efetivamente, os direitos humanos passaram a contar com os mecanismos para sua proteção e defesa. O Estatuto da Comissão, definitivamente adotado em 1960, estabeleceu o seu caráter de entidade autônoma da Organização, composta por sete membros, eleitos por seu Conselho a título pessoal, com as funções de promover o respeito dos direitos humanos, assim entendidos aqueles que compunham a Declaração Americana de Direitos e Deveres do Homem. Em consequência disso, a Declaração adquiriu força jurídica, eis que se converteu no documento básico para a atuação da Comissão Interamericana.
\end{abstract}

Para alcançar o objetivo de promover a efetividade e a defesa dos direitos humanos na América, a Convenção Americana elenca, em seu artigo 41, as seguintes funções e atribuições para a Comissão: a) estimular a consciência dos direitos humanos nos povos da América; b) formular recomendações aos governos dos Estados membros, quando o considerar conveniente, no sentido de que adotem medidas progressivas em prol dos direitos humanos no âmbito de suas leis internas e seus preceitos constitucionais, bem como disposições apropriadas para promover o devido respeito a esses direitos; c) preparar os estudos ou relatórios que considerar convenientes para o desempenho de suas funções; d) solicitar aos governos dos Estados membros que the proporcionem informações sobre as medidas que adotarem em matéria de direitos humanos; e) atender às consultas que, 
por meio da Secretaria-Geral da Organização dos Estados Americanos, Ihe formularem os Estados membros sobre questões relacionadas com os direitos humanos e, dentro de suas possibilidades, prestar-Ihes o assessoramento que eles Ihe solicitarem; f) atuar com respeito às petições e outras comunicações, no exercício de sua autoridade, de conformidade com o disposto nos artigos 44 a 51 desta Convenção; e g) apresentar um relatório anual à Assembleia Geral da Organização dos Estados Americanos.

Dentre as suas competências, a principal, embora não mais importante que as demais, é a de "examinar as comunicações de indivíduos ou grupos de indivíduos, ou ainda de entidade não governamental legalmente reconhecida em um ou mais Estados-membros da OEA, atinentes a violações de direitos humanos constantes da Convenção Americana" por um Estado-membro. Isto é, qualquer pessoa, seja nacional ou não do Estado em que se encontra, que sofreu violação de direitos humanos arrolados nesta Convenção poderá submeter uma petição à Comissão. ${ }^{8}$ Ainda, é importante lembrar que, o Estado, tornando-se membro da Convenção, reconhece simultaneamente - e obrigatoriamente - "a competência da Comissão para examinar essas comunicações, não sendo necessário elaborar declaração expressa e específica para tal fim" (PIOVESAN, 2008, p. 249).

Entretanto, a petição que alegar violação de direitos humanos reconhecidos pela Convenção Americana deve preencher alguns requisitos de admissibilidade expressos no artigo 46, 1, da Convenção Americana.Primeiramente, é necessário que hajam sido interpostos e esgotados os recursos da jurisdição interna do Estado de que são nacionais, isto porque o sistema regional de proteção tem caráter complementar ao sistema interno de cada Estado-Parte. Assim, deve ser dada a oportunidade para que o Estado solucione internamente o caso, e somente se ele falhar ou for omisso poderá a vítima promover o processo internacional, neste caso frente a Comissão ${ }^{9}$. Esse requisito não terá aplicação apenas quando não

\footnotetext{
${ }^{8}$ Artigo 44 da Convenção Americana de Direitos Humanos: "Qualquer pessoa ou grupo de pessoas, ou entidade não-governamental legalmente reconhecida em um ou mais Estados membros da Organização, pode apresentar à Comissão petições que contenham denúncias ou queixas de violação desta Convenção por um Estado Parte".

${ }^{9}$ Sobre esse requisito, frisam os autores: "[...] o propósito da regra não é incentivar situações burocráticas insolúveis para que os peticionários nunca possam ter acesso ao sistema, mas
} 
existir, na legislação interna do Estado de que se tratar, o devido processo legal para a proteção do direito ou direitos que se alegar violação ou quando não se houver permitido ao presumido prejudicado em seus direitos o acesso aos recursos da jurisdição interna, ou houver sido ele impedido de esgotá-los. Também, é necessário que seja essa petição seja apresentada dentro do prazo de seis meses, a partir da data em que o presumido prejudicado em seus direitos tenha sido notificado da decisão definitiva; ou seja, tendo o caso sido submetido à jurisdição interna do Estado, o prejudicado em seus direitos deverá propor a petição dentro de seis meses da ciência da última decisão, salvo quando houver demora injustificada na decisão, caso em que não será aplicado tal requisito. Ainda, faz-se necessário que a matéria da petição ou comunicação não esteja pendente de outro processo de solução internacional; isto é, é vedado que um mesmo caso esteja simultaneamente sob apreciação de mais de um órgão internacional. E, ainda, é preciso que a petição contenha o nome, a nacionalidade, a profissão, o domicílio e a assinatura da pessoa ou pessoas ou do representante legal da entidade que submeter a petição (PIOVESAN, 2008, p. 249 et seq.).

Recebida a petição ou comunicação, a Comissão deverá, se reconhecer a sua admissibilidade, solicitar informações ao governo do Estado ao qual pertença a autoridade apontada como responsável pela violação alegada, sendo que essas informações deverão ser enviadas pelo Estado para a Comissão dentro de um prazo razoável estabelecido por ela, levando-se em consideração as circunstâncias do caso. Recebidas as informações dadas pelo Estado, ou transcorrido o prazo fixado sem recebê-las, verificará se existem ou subsistem os motivos da comunicação. Não existindo, ou não subsistindo, o expediente será arquivado. Contudo, se for verificado que os motivos continuam, a Comissão procederá um exame ou investigação sobre o assunto descrito na petição com a finalidade de comprovar os fatos, tudo isso com o conhecimento das partes (MAZZUOLI, 2011, p. 886-887).

Feita a análise do caso, a Comissão buscará uma solução amistosa entre as partes (peticionário e Estado-membro), segundo o artigo 49 da Convenção Americana. Se o acordo for alcançado, elaborar-se-á um relatório

como estímulo à solução das violações de direitos humanos pelo fortalecimento das vias internas". (GORESTEIN; HIDAKA; LIMA JR., 2002, p. 90). 
contendo uma breve exposição dos fatos e da solução dada, que será encaminhado para as partes e, posteriormente, para o Secretário Geral da Organização dos Estados Americanos, para que seja publicado (MAZZUOLI, 2011, p. 887).

Entretanto, se não ocorrer conciliação, será elaborado um relatório expondo os fatos e as conclusões (que dirão se o Estado violou a Convenção Americana ou não), e, também, as eventuais recomendações ao Estado. Este relatório é encaminhado ao Estado-membro, que terá três meses para "conferir cumprimento das recomendações feitas". Durante esse período, o caso pode ser solucionado pelas partes ou submetido à apreciação da Corte Interamericana de Direitos Humanos. Porém, se não for dado prosseguimento a nenhuma dessas opções, a própria Comissão, por maioria absoluta de votos, poderá emitir opinião - com recomendações pertinentes ao Estado, bem como fixará prazo para que tome as medidas necessárias para reparar os danos causados e regularizar a situação. Vencido o prazo, a Comissão "decidirá, por maioria absoluta de votos de seus membros, se as medidas recomendadas foram adotadas e se publicará o informe por ela elaborado no relatório anual de suas atividades" (PIOVESAN, 2008, p. 252).

\subsection{Corte Interamericana de Direitos Humanos}

A Corte Interamericana de Direitos Humanos - "segundo órgão da Convenção Americana" - é o órgão jurisdicional do sistema interamericano, ou seja, cuida-se do órgão competente para julgar os casos de violação de direitos humanos praticados pelos Estados-membros da OEA que tenham ratificado a Convenção Americana de Direitos Humanos - tendo natureza de órgão judiciário internacional. É um verdadeiro "tribunal internacional supranacional, capaz de condenar os Estados-partes na Convenção Americana por violação de direitos humanos" (MAZZUOLI, 2011, p. 889).

Sua origem ocorreu em 1978, com a entrada em vigor da Convenção Americana. No entanto, só passou a funcionar efetivamente em 1980, ocasião em que emitiu sua primeira opinião consultiva; e, principalmente, em 1987, quando proferiu sua primeira sentença (MAZZUOLI, 2011, p. 889). 
A Corte Interamericana detém competência consultiva e contenciosa. A primeira é relativa à interpretação das disposições da Convenção Americana, bem como das disposições de tratados concernentes à proteção dos direitos humanos nos Estados Americanos, segundo o artigo 64 da Convenção. Já a segunda tem caráter jurisdicional, com a finalidade de julgar casos concretos de violações de direitos humanos elencados na Convenção Americana por um de seus Estados-membros, regulada pelos artigo 61 a 63 da Convenção.

Ao ratificarem a Convenção, os Estados-partes aceitam automaticamente a competência consultiva da Corte, por outro lado a sua competência contenciosa é facultativa e, por isso, deve ser reconhecida expressamente pelo Estado para que, então, este possa ser demandado perante a Corte se violar direitos humanos de seus nacionais (PIOVESAN, 2008, p. 254-256). Sobre esta limitação da jurisdição da Corte, expressa no artigo 62 da Convenção, critica Piovesan (2008, p. 258):

[...] este dispositivo constitui um anacronismo histórico, que deve ser superado, a fim de que se consagre o "automatismo da jurisdição obrigatória da Corte para todos os Estados-partes da Convenção". Isto é, todo Estado-parte da Convenção passaria a reconhecer como obrigatória, de pleno direito e sem convenção especial, integralmente e sem restrição alguma, a competência da Corte em todos os casos relativos à interpretação e aplicação da Convenção.

Embora a Convenção, ao tornar facultativa a competência da Corte Interamericana, tenha adotado uma estratégia de política internacional para que os Estados ratificassem a Convenção sem ter receio de serem demandados prontamente por violações de direitos humanos para que mais tarde ratificassem, também, a competência da Corte, é mais importante a proteção integral do indivíduo desde a ratificação da Convenção, tornando obrigatório, desde logo, a competência da Corte (MAZZUOLI, 2011, p. 890).

Surpreendentemente, na contramão de promover a participação e o acesso a justiça, a Convenção prevê, em seu artigo 61, legitimidade para submeter um caso à Corte Interamericana somente a Comissão Interamericana e aos Estados que the fazem parte, não estando prevista a legitimação dos indivíduos (PIOVESAN, 2008, p. 252). Sobre este assunto, prevê Mazzuoli (2011, p. 891) que: 
Não obstante os indivíduos (vítimas das violações de direitos humanos ou seus representantes) não poderem ainda demandar diretamente à Corte Interamericana, a projeção que se faz para o futuro, relativamente à sua capacidade processual internacional, é que a ideia de locusstandi in judicio (ou seja, do direito de "estar em juízo" em todas as etapas do procedimento perante a Corte, tal como autoriza $\circ$ art. 25, $\S 1^{\circ}$, do seu atual Regulamento) evolua para a possibilidade do reconhecimento dos indivíduos peticionarem diretamente ao tribunal interamericano (à guisa do que já ocorre no europeu) em casos concretos de violações de direitos humanos, consagrando-se o desejado jus standi in judicio (ou seja, o direito de "ingressar em juízo" diretamente). Enquanto isso não ocorre, ao menos o direito de participação das supostas vítimas ou seus representantes durante todo o processo (locusstandi) já está assegurado, desde o anterior Regulamento da Corte Interamericana (2000) até o seu Regulamente atual (2009).

Sob a mesma linha de pensamento, Boucalt e Araujo (1999, p. 19) argumentam:

[...] ao reconhecimento de direitos, nos planos tanto nacional como internacional, corresponde a capacidade processual de vindicá-los ou exercê-los. A proteção de direitos deve ser dotada do locusstandi in judicio das supostas vítimas (ou de seus representantes legais), que contribui para melhor instruir o processo, e sem o qual estará este último desprovido em parte do elemento do contraditório (essencial na busca da verdade e da justiça), ademais de irremediavelmente mitigado e em flagrante desequilíbrio processual. É da própria essência do contencioso internacional dos direitos humanos o contraditório entre as vítimas de violações e os Estados demandados. Tal locusstandi é a consequência lógica, no plano processual, de um sistema de proteção que consagra direitos individuais no plano internacional, porquanto não é razoável conceber direitos sem a capacidade processual de vindicá-los.

Assim, se espera que a Convenção evolua nesse sentido, dando a oportunidade de também os indivíduos peticionarem diretamente na Corte Interamericana quando não for alcançada uma solução para o seu caso na Comissão Interamericana de Direitos Humanos. Direito este - de locusstandi in judicio - imprescindível para a verdadeira consolidação da plena personalidade internacional e capacidade jurídica e processual dos cidadãos.

Então, esta Corte tem competência para examinar e julgar os casos de violações de direitos humanos por parte dos Estados que ratificaram a sua competência e passaram, anteriormente, pela Comissão Interamericana de Direitos Humanos, e que, agora, Ihe foram submetidos para apreciação. Se reconhecer que realmente houve violação desses direitos, determinará que o Estado adote as medidas necessárias para restaurar o direito violado. A sua decisão, ou sentença, "tem força jurídica vinculante e obrigatória, cabendo ao 
Estado seu imediato cumprimento" (PIOVESAN, 2008, p. 259). Nesse sentido, explica Mazzuoli (2011, p. 891):

\begin{abstract}
A Corte não relata casos e não faz qualquer tipo de recomendação no exercício de sua competência contenciosa, mas profere sentenças, que segundo o Pacto de San José são definitivas e inapeláveis. Ou seja, as sentenças da Corte são obrigatórias para os Estados que reconheceram a sua competência em matéria contenciosa. Quando a Corte declara a ocorrência de violação de direito resguardado pela Convenção, exige a imediata reparação do dano, e impõe, se for 0 caso, o pagamento de justa indenização à parte lesada.
\end{abstract}

Para consolidar a obrigatoriedade da declaração de violação de direitos humanos proferida pela Corte, prevê o artigo 68, que os Estados comprometem-se a cumprir a sentença em todos os casos em que forem partes. Além disso, dispõe que a parte da sentença que determinar indenização compensatória poderá ser executada no país respectivo pelo processo interno vigente para a execução de sentenças contra o Estado (BOUCALT; ARAUJO, 1999, p. 27).

A partir disso, conclui-se que a Corte Interamericana de Direitos Humanos é um grande avanço para a proteção dos direitos humanos nas Américas, dando uma solução aos casos de violações de direitos humanos através de suas sentenças, que tem caráter obrigatório. No entanto, é necessário, ainda, que se aperfeiçoe em alguns aspectos, como o direito de petição para os indivíduos (locusstandi in judicio) e cláusula de jurisdição obrigatória, para que sua proteção seja verdadeiramente, e ainda mais, eficaz.

\title{
4.2.1. Eficácia Interna das Sentenças Proferidas pela Corte Interamericana de Direitos Humanos
}

Todo Estado, ao ratificar a Convenção Americana de Direitos Humanos, se compromete a cumprir as sentenças que the forem impostas pela Corte Interamericana de Direitos Humanos, ou seja, suas decisões tem caráter obrigatório. No entanto, há uma "questão jurídica complexa" acerca das sentenças proferidas pela Corte - e também por quaisquer tribunais internacionais - em relação à necessidade, ou não, de serem homologadas pelo Superior Tribunal de Justiça para que tenham eficácia interna no Estado Brasileiro (MAZZUOLI, 2011, p. 895). 
Segundo o artigo 105, inciso I, alínea i, da Constituição Federal Brasileira, compete ao Superior Tribunal de Justiça a homologação de sentenças estrangeiras, regra esta que repetida pelo artigo 483 do Código de Processo Civil. ${ }^{10}$

$\mathrm{Na}$ interpretação desses artigos é necessário levar em consideração a diferença entre sentença estrangeira e sentença internacional. Sentença estrangeira, como se referem os artigos citados, é aquela proferida por "um tribunal afeto à soberania de determinado Estado", ou seja, uma decisão proferida por um órgão judiciário que faz parte de outro Estado, também soberano. Já, sentença internacional é aquela "emanada de um tribunal internacional que tem jurisdição sobre os seus próprios Estados-Partes". Desse modo, embora ambas tenham em comum a característica de não provirem de autoridade judiciária nacional, não se confundem (MAZZUOLI, 2011, p. 896).

Conclui-se, então, que as sentenças estrangeiras necessitam ser homologadas pelo Supremo Tribunal Federal para terem eficácia interna no Brasil. Já para a eficácia das sentenças internacionais não há esse requisito (MAZZUOLI, 2011, p. 895).

A Corte Interamericana trata-se de verdadeiro tribunal internacional, o qual o Estado Brasileiro aceitou a jurisdição; por conseguinte, as sentenças que proferir serão sentenças internacionais - "ato judicial emanado de órgão judiciário internacional de que o Estado faz parte" - e, portanto, não precisam ser homologadas pelo Supremo Tribunal de Justiça para que se tornem eficazes internamente. Isto é, o Estado Brasileiro estará obrigado a cumprir de plano a sentença como faria com decisão de seu Poder Judiciário (MAZZUOLI, 2011, p. 895-896).

No entanto, há, ainda, um impasse quanto a execução das sentenças proferidas pela Corte, sendo necessária a construção de um "sistema eficaz" no ordenamento jurídico interno para que sejam efetivamente cumpridas pelo Estado Brasileiro quando condenado a restauração de direitos e indenização das vítimas de violações; não obstante a Convenção Americana declare expressamente em seu artigo 68, 1, que "os Estados Partes na Convenção comprometem-se a cumprir a decisão da Corte em todo caso em que forem

\footnotetext{
${ }^{10}$ Artigo 483 do Código de Processo Civil: "A sentença proferida por tribunal estrangeiro não terá eficácia no Brasil senão depois de homologada pelo Supremo Tribunal Federal”.
} 
partes". Em verdade, o problema não se encontra na obrigação de indenizar (a qual deve ser cumprida sponte sua, isto é, paga imediatamente), mas nas obrigações - ou deveres - implícitas de investigação e punição dos culpados pela violação aos direitos da vítima (MAZZUOLI, 2011, p. 897 et seq.).

Para a solução de tal problema, faz-se necessária a adoção de legislação interna referente à recepção e exigibilidade das sentenças da Corte pelo Estado Brasileiro, uma vez que "a efetividade da proteção internacional dos direitos humanos está absolutamente condicionada ao aperfeiçoamento das medidas nacionais de implementação" (PIOVESAN, 2008, p. 271).

\section{ILUSTRAÇÃO PRÁTICA: CASO DAMIÃO XIMENES LOPES}

O caso Damião Ximenes Lopes resultou na primeira condenação do Estado Brasileiro pela Corte Interamericana de Direitos Humanos em função da violação dos direitos das pessoas portadoras de deficiências mentais - direitos estes previstos na Convenção Americana sobre Direitos Humanos. Sendo, também a primeira sentença proferida pela Corte sobre este assunto (MAZZUOLI, 2011, p. 898).

No dia $1^{\circ}$ de outubro de 1999, o Sr. Damião Ximenes Lopes, portador de transtornos mentais, foi internado por sua mãe, Albertina Ximenes, em um centro de saúde que funcionava à base do Sistema Único de Saúde (serviço público de assistência médica), denominado Casa de Repouso Guararapes, localizado no Município de Sobral, Estado do Ceará, para o seu tratamento psiquiátrico. No entanto, três dias após a sua internação a vítima faleceu sob os cuidados da referida clínica (FRIEDRICH, 2006, p. 18 et seq.). Friedrich (2006, p. 18-19) relata os detalhes do caso:

Damião Ximenes Lopes, portador de transtorno mental e epilepsia, havia sido internado por sua mãe, Albertina Ximenes, na única clínica psiquiátrica da região da cidade de Sobral, no Ceará, no dia $1^{\circ}$ de outubro de 1999. Três dias depois, indignada, a mãe forçou a entrada na clínica, pois foi informada por um funcionário que seu filho não tinha condições de receber visitas. Encontrou Damião com as mãos amarradas, passando muito mal, sangrando e apresentando escoriações e hematomas, decorrentes de briga com os enfermeiros da Clínica. De volta para casa, recebeu a notícia de que seu filho havia morrido, por parada respiratória. 
Depois do ocorrido, a família de Damião Ximenes procurou vários órgãos internos - como a Polícia local, o Ministério Público e até mesmo a Comissão de Direitos Humanos da Assembleia Legislativa do Ceará - com a finalidade de alcançar justiça para o caso. No entanto, suas tentativas foram improdutivas, o que levou a buscar um organismo internacional: o Sistema Interamericano (FRIEDRICH, 2006, p. 19).

Então, no dia 22 de novembro de 1999, os familiares da vítima, assistidos por uma organização não-governamental denominada Justiça Global, enviaram uma comunicação (ou denúncia) à Comissão Interamericana de Direitos Humanos, que foi recepcionada em 9 de outubro de 2002. E em $1^{\circ}$ de outubro de 2004 a Comissão, por não conseguir solucionar o caso, enviou-o para o órgão jurisdicional do Sistema Interamericano, a fim de se verificar a violação da Convenção principalmente em quatro artigos: o 4ำ (direito à vida), 0 $5^{\circ}$ (direito à integridade física), o $8^{\circ}$ (garantias judiciais) e 0 25을 (direito à proteção judicial). (FRIEDRICH, 2006, p. 23)

Primeiramente, o Estado Brasileiro propôs uma exceção preliminar de não-esgotamento da jurisdição interna, que não foi acolhida pela Corte. Depois disso, reconheceu a sua "responsabilidade internacional pela violação dos artigos 4ำ e 5 da Convenção Americana" (FRIEDRICH, 2006, p. 27).

A sentença foi proferida pela Corte Interamericana no dia 4 de julho de 2006 reconhecendo, por unanimidade, a responsabilidade do Brasil pela violação de todos os direitos a que havia sido acusado: os direitos à vida e a integridade pessoal de Damião Ximenes Lopes - que já haviam sido reconhecidas - e dos direitos às garantias judiciais e à proteção judicial dos familiares da vítima. Além disso, declarou, também por unanimidade, que o Estado deve garantir a efetividade do processo interno destinado a investigar e sancionar os responsáveis pelo fato; deve, também, continuar a desenvolver e aperfeiçoar os programas de formação e capacitação dos profissionais de atendimento psiquiátrico, sobretudo quanto aos princípios que regem esse trabalho, conforme os padrões internacionais; e deve pagar indenização por dano material, imaterial e custas processuais, no valor total de US\$146 mil, para os familiares da vítima (FRIEDRICH, 2006, p. 27-28). 
Até então, o Estado só havia sido demandado na Comissão Interamericana por casos envolvendo policiais militares ou questões agrárias. Melhor seria que nunca promovesse ou se omitisse em casos de violação de direitos humanos. No entanto, o reconhecimento das violações do direito à vida e da integridade física no Caso Damião Ximenes demonstra um posicionamento consciente do Estado Brasileiro em relação à jurisdição da Corte Interamericana.

\section{CONSIDERAÇÕES FINAIS}

O movimento de internacionalização dos direitos humanos (e a formação do Direito Internacional dos Direitos Humanos) culminou com a criação dos sistemas internacionais de proteção dos direitos humanos e, mais adiante, os sistemas regionais.

A consecução deste meio não convencional de participação - a qual se exerce através de denúncias à Comissão Interamericana, que poderá submeter o caso concreto à Corte Interamericana - só foi possível em função de o Estado Brasileiro consistir em um Estado Democrático de Direito, e consequentemente, ter o Princípio da Participação implícito em seu texto constitucional.

Nesse contexto, o Estado Brasileiro está inserido no Sistema Interamericano de Proteção dos Direitos Humanos - tendo como diploma fundamental a Convenção Interamericana de Direitos Humanos - e, portanto, é possível aos cidadãos brasileiros alcançar a reparação de danos e o restabelecimento dos direitos que foram violados pelo seu Estado por meio desse órgão internacional.

A partir disso, o sistema americano - com suporte de seus principais órgãos, quais sejam, a Comissão e a Corte Interamericana de Direitos Humanos - emerge como um novo meio não convencional eficaz na salvaguarda dos direitos humanos, uma vez que tem jurisdição para examinar e julgar os casos submetidos a sua apreciação e, se constatar a violação de direitos humanos por parte de um de seus Estados-membros buscará a solução para o caso; primeiramente de modo amistoso, não sendo possível, 
proferirá sentença condenatória obrigatória, que terá eficácia interna no Estado Brasileiro, independentemente de qualquer ato de homologação nacional.

No entanto, para a efetiva proteção dos direitos humanos, é necessário, ainda, o aperfeiçoamento do Sistema Interamericano de Proteção dos Direitos Humanos em alguns aspectos.

Primeiramente, é importante que seja concedido o direito de petição direta à Corte Interamericana - locusstandi in judicio - às supostas vítimas de violação de direitos humanos (ou seus representantes legais), prescindindo até mesmo da análise pela Comissão Interamericana para isto, pois, uma vez que a Convenção Americana prevê direitos individuais, é razoável que preveja, também, um modo de acesso democrático ao seu órgão jurisdicional. Isto é, embora a participação dos cidadãos à Corte seja possível e eficaz (através da Comissão Interamericana), é de suma importância, para satisfazer o princípio do contraditório, que os próprios cidadãos possam decidir submeter seu caso à Corte, e não somente a Comissão e os Estados demandados.

Também, é relevante que o Sistema evolua quanto a facultatividade da competência contenciosa da Corte. Em outras palavras, todos os Estados deveriam aceitar automaticamente esta jurisdição da Corte ao tornarem-se membros da Convenção Americana - como uma cláusula de jurisdição obrigatória -, sem a necessidade de seu reconhecimento expresso para que possa ser demandado. Desse modo, sem a necessidade de reconhecimento, os cidadãos poderão demandar contra o Estado desde logo, quando ratificada a Convenção, tornando mais integral a sua proteção.

Por fim, é imprescindível que o Estado Brasileiro adote legislação doméstica referente à recepção e exigibilidade internas das sentenças da Corte Interamericana, para que estas sejam cumpridas de forma satisfatória.

Sobretudo, mesmo carecendo de mudanças, o Sistema Interamericano mostra-se um meio eficaz na proteção dos direitos humanos, uma vez que salvaguarda muitas vidas e contribui sobremaneira na concretização do Estado Democrático de Direito em todas as Américas e especialmente tem assegurado ás vítimas o direito à esperança de que a justiça seja feita em outra entidade quando o seu Estado não o faz. 


\section{REFERÊNCIAS}

BRAGATO, Fernanda Frizzo; CULLETON, Alfredo; FAJARDO, Sinara Porto. Curso de Direitos Humanos. São Leopoldo: Unisinos, 2009.

BRASIL. Constituição Estadual do Estado do Rio Grande do Sul, promulgada em 3 de outubro de 1989. Porto Alegre, Rio Grande do Sul, 1989.

BRASIL.Constituição da República Federativa do Brasil, promulgada em 5 de outubro de 1988. Brasília, Distrito Federal: Senado, 1988.

BRASIL.Decreto no 678, de 6 de novembro de 1992. Promulga a Convenção Americana sobre Direitos Humanos (Pacto de São José da Costa Rica), de 22 de novembro de 1969. Brasília, 6 de novembro de 1992. Disponível em: $<$ http://www.planalto.gov.br/ccivil_03/decreto/D0678.htm>. Acesso em: 22 dez. 2011.

BRASIL.Lei no 5.869, de 11 de janeiro de 1973. Institui o Código de Processo Civil. Brasília, 11 de janeiro de 1973. Disponível em: <http://www.planalto.gov.br/ccivil_03/leis/L5869compilada.htm>. Acesso em: 22 dez. 2011.

BOBBIO, Norberto. A Era dos Direitos. Tradução de Carlos Nelson Coutinho. Rio de Janeiro: Campus, 1992.

BOUCALT, Carlos E. A.; ARAUJO, Nadia (Org.). Os Direitos Humanos e o Direito Internacional. Rio de Janeiro: Renovar, 1999.

COMPARATO, Fábio Konder. A afirmação histórica dos direitos humanos. $7^{a}$ edição. São Paulo: Saraiva, 2010.

Convenção Americana de Direitos Humanos.22 de novembro de 1969. Disponível em: <http://www.planalto.gov.br/ccivil_03/decreto/19901994/anexo/and678-92.pdf >. Acesso em: 22 dez. 2011.

CORRÊA, Darcísio. A construção da cidadania:Reflexões histórico-políticas. 3ª edição. ljuí: UNIJUÍ, 2002.

Declaração Universal de Direitos Humanos de 1948. Disponível em: <http://www.ohchr.org/EN/UDHR/Documents/UDHR_Translations/por.pdf>. Acesso em: 22 dez. 2011.

DEMO, Pedro. Participação é conquista. 3ํe edição. São Paulo: Cortez, 1999.

FRIEDRICH, Tatyana Scheila. Sistema Interamericano de Proteção de Direitos Humanos: uma análise a partir do caso Damião Ximenes Lopes. Revista Brasileira de Direito Internacional, Curitiba, v. 3, n. 3, p. 18-29, jan./jun. 2006. 
GENTILE, Jorge Horacio. El fundamento de los derechos humanos. Revista Brasileira de Direito Constitucional, São Paulo, v. 2, n. 6, p. 56-63, jul./dez. 2005.

GORESTEIN, Fabiana; HIDAKA, Leonardo Jun F.; LIMA JR., Jayme Benvenuto. Manual de Direitos Humanos Internacionais: Acesso aos Sistemas Global e Regional de Proteção dos Direitos Humanos. São Paulo: Loyola, 2002.

KANT, Immanuel. À paz perpétua. Tradução de Marco Zingano. Porto Alegre: L\&PM, 2010.

LUCAS, John Randolph. Democracia e Participação. Tradução de Cairo Paranhos Rocha. Brasília: Editora Universidade de Brasília, 1985.

MARCANTE, Sheron; TOAZZA, Vinícius Francisco. 2010. Os princípios na concepção sistêmica do direito contemporâneo. Revista da Faculdade de Direito da UPF, Passo Fundo, v. 3, p. 40-51, jan./dez. Disponível em $<$ http://www.upf.br/direito/images/stories/direito_online_v3_2010.pdf >

MAZZUOLI, Valerio de Oliveira. Curso de Direito Internacional Público. $5^{\text {a }}$ edição. São Paulo: Revista dos Tribunais, 2011.

MELLO, Celso Antônio Bandeira de. Curso de Direito Administrativo. 26 edição. São Paulo: Malheiros, 2009.

MORAES, Alexandre de. Direitos Humanos Fundamentais: Teoria Geral. 9a edição. São Paulo: Atlas, 2011.

MOREIRA NETO, Diogo de Figueiredo. Mutações do Direito Administrativo. $2^{a}$ edição. Rio de Janeiro: Renovar, 2001.

. Mutações do Direito Público. Rio de Janeiro: Renovar, 2006.

PEREIRA, André G.; QUADROS, Fausto de. Manual de Direito Internacional

Público. 3aㅗ. edição. Coimbra: Livraria Almedina, 1997.

PIOVESAN, Flávia. Direitos Humanos e o Direito Constitucional Internacional. 9ª edição. São Paulo: Saraiva, 2008.

Limonard, 2003.

Temas de Direitos Humanos. $2^{\mathrm{a}}$ edição. São Paulo: Max

SANTIN, Janaína Rigo. 2006. O princípio da participação no regime jurídico-administrativo brasileiro. Revista Brasileira de Direito Constitucional. São Paulo, v 2, p. 42-72.

SARLET, Ingo Wolfgang. A Eficácia dos Direitos Fundamentais:Uma teoria geral dos direitos fundamentais na perspectiva constitucional. $10^{2}$ edição. Porto Alegre: Livraria do Advogado, 2009. 
TEIXEIRA, Elenaldo. O local e o global: Limites e desafios da participação cidadã. $3^{\underline{a}}$ edição. São Paulo: Cortez, 2002.

Recebido para publicação: 09/10/2012

Aceito para publicação: 19/12/2012 